\title{
AEROMAGNETIC MAP OF THE RAMSEY QUADRANGLE, PASSAIC AND BERGEN COUNTIES, NEW JERSEY, AND ROCKLAND COUNTY, NEW YORK
} By

John R. Henderson, Evelyn J. Chandler, and others

GEOPHYSICAL INVESTIGATIONS

MAP GP-344

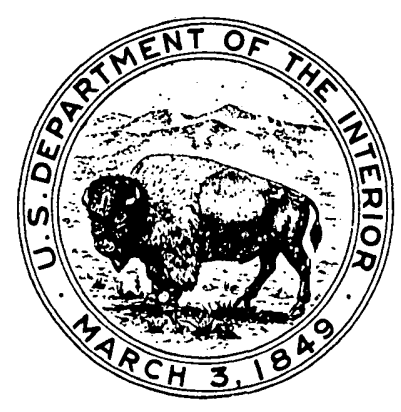

